\title{
Sosialisasi Keselamatan dan Keamanan Laboratorium IPA di SMA 1 Pangkalan Baru, Kampar
}

\author{
Arief Yandra Putra*1, Fitri Mairizki² \\ 1Program Studi Pendidikan Kimia, Fakultas IKIP, Universitas Islam Riau \\ ${ }^{2}$ Program Studi Teknik Geologi, Fakultas Teknik, Universitas Islam Riau \\ *e-mail : ariefyandra0811@edu.uir.ac.id
}

\begin{abstract}
The laboratory has an important role in the teaching and learning process. The laboratory with all its materials and equipments is a place that has the potential to cause danger for humans and the environment. Laboratory safety and security management are the responsibility of both the laboratory assistant and laboratory user. Based on the initial survey, the school already has a science laboratory but the tools and materials are poorly organized and poorly administered. The method used in this community service were socialization about the organization and administration of laboratory, socialization about safety and security laboratories related to the management of laboratory equipments and materials, demonstration and evaluation. In general, this community service activity ran successfully as planned. Participants in the activity were very enthusiastic and actively participated during the activity. Based on evaluation results, it was known that students' knowledge about laboratory safety and security has increased after participating in this community service.
\end{abstract}

Keywords: Laboratory, management, safety, security

\begin{abstract}
Abstrak
Laboratorium memiliki peranan penting dalam proses belajar mengajar. Laboratorium dengan segala kelengkapan bahan dan peralatan merupakan tempat yang berpotensi menimbulkan bahaya bagi manusia dan lingkungan. Pengelolaan keselamatan dan keamanan laboratorium merupakan tanggung jawab bersama baik pengelola laboratorium maupun pengguna laboratorium. Berdasarkan survei awal, sekolah sudah memiliki laboratorium IPA namun alat dan bahan yang ada kurang tertata dan kurang teradministrasi dengan baik. Metode yang digunakan dalam pengabdian masyarakat ini adalah sosialisasi tentang organisasi dan administrasi laboratorium, sosialisasi tentang keselamatan dan keamanan laboratorium terkait tata kelola alat-alat dan bahan laboratorium, demonstrasi dan evaluasi. Secara umum, kegiatan pengabdian masyarakat ini berjalan sukses dan sesuai dengan yang telah direncanakan. Peserta kegiatan sangat antusias dan berpartisipasi secara aktif selama kegiatan berlangsung. Berdasarkan hasil evalusi, diketahui bahwa pengetahuan siswa tentang keselamatan dan keamanan laboratorium mengalami peningkatan setelah mengikuti kegiatan pengabdian masyarakat ini.
\end{abstract}

Kata kunci: Laboratorium, pengelolaan, keselamatan, keamanan

\section{PENDAHULUAN}

Kebijakan umum Kementrian Pendidikan dan Kebudayaan Republik Indonesia (Kemendikbud RI), khususnya yang berkenaan dengan pendidikan Sekolah Menengah Atas (SMA), diarahkan kepada peningkatan mutu melalui peningkatan proses pembelajaran di kelas. Hal ini dituangkan dalam Permendikbud No. 65 tahun 2013 tentang Standar Proses Pendidikan Dasar. Permendikbud tersebut menuntut penyediaan sumber belajar, penyediaan alat dan sarana pembelajaran yang memadai sebagai komponen penting dalam proses pendidikan. Salah satu sarana pembelajaran yang harus disediakan adalah laboratorium (Panggabean, F., T., M., Kawan S., dan Murniaty, S., 2017). Penerapan kurikulum 2013 menekankan kepada kegiatan pembelajaran melalui tahapan identifikasi masalah, pengamatan, pengumpulan data, analisis data, penarikan kesimpulan bahkan pengujian ulang untuk membuktikan kesimpulan. Semua tahapan tersebut diperoleh melalui proses pembelajaran di kelas maupun di laboratorium (Erna, M., Johni, A., dan Sri, W., A., 2020).

Laboratorium memiliki peranan penting dalam proses belajar mengajar. Konsep yang disampaikan di kelas dapat dipahami secara baik dengan adanya pengamatan langsung terhadap fenomena-fenomena alam melalui aktivitas di laboratorium berupa praktikum. Praktikum yang 
dilaksanakan di laboratorium bertujuan untuk memperdalam pemahaman terhadap konsep yang telah diajarkan di kelas. Oleh karena itu, laboratorium merupakan salah satu sarana yang harus disediakan oleh penyelenggara sekolah untuk menunjang kegiatan belajar (Sinaga, M., Z., E., Yuan, A., S., dan Aghni, S., 2018).

Laboratorium adalah unit penunjang akademik pada lembaga pendidikan, berupa ruangan tertutup atau terbuka, bersifat permanen atau bergerak, dikelola secara sistematis untuk kegiatan pengujian, kalibrasi, dan/atau produksi dalam skala terbatas, dengan menggunakan peralatan dan bahan berdasarkan metode keilmuan tertentu, dalam rangka pelaksanaan pendidikan, penelitian, dan/atau pengabdian kepada masyarakat. Oleh karena itu, laboratorim perlu dikelola oleh teknisi/laboran yang dikenal sebagai Pranata Laboratorium (Raharjo, 2017).

Laboratorium dengan segala kelengkapan bahan dan peralatan merupakan tempat berpotensi menimbulkan bahaya bagi manusia dan lingkungan. Resiko kecelakaan dalam bekerja dapat terjadi pada setiap pekerjaan yang dapat memberikan dampak bagi keselamatan dan kesehatan baik secara fisik, mental dan sosial (Subiantoro, A., W., 2011). Resiko kecekaan kerja di laboratorium khususnya laboratorium IPA dapat berasal dari bahan yang digunakan karena mengandung bahan yang bersifat korosif, mudah terbakar, oksidator kuat, bersifat iritan, bersifat beracun dan bersifat mudah meledak. Sarana di laboratorium seperti pemakaian gas, pemakaian air, pemakaian listrik dan peralatan gelas juga dapat menjadi sumber bahaya dalam laboratorium. Jenis-jenis bahaya yang sering menimbulkan kecelakaan dalam laboratorium adalah keracunan, iritasi, kebakaran, luka bakar, dan luka kulit (Isnainy, H., Hamzah, H., dan Rico, J., S., 2014). Letak laboratorim yang terlalu dekat dengan ruang kelas juga beresiko menimbulkan bahaya bagi lingkungan seperti kebakaran dan pencemaran udara (Mauliza, Ratih., P., S., dan Nurhafidhah, 2017). Ketersediaan fasilitas terkait keselamatan dan keamanan laboratorium juga perlu diperhatikan sebagai upaya untuk meminimalisir terjadinya kecelakaan kerja (Rahmantiyoko, A., dkk, 2019).

Pengelolaan keselamatan dan keamanan laboratorium merupakan tanggung jawab bersama baik pihak pengelola maupun pihak pengguna (Dewan Ilmu Pengetahuan dan Teknologi Kimia, 2010). Oleh karena itu, setiap orang yang terlibat harus memiliki kesadaran untuk mengatur, memelihara, dan mengusahakan keselamatan kerja. Upaya mengatur dan memelihara bertujuan agar laboratorium selalu tetap berfungsi sebagaimana mestinya. Guru dan siswa merupakan pengguna fasilitas laboratorium yang perlu memiliki pengetahuan yang cukup dalam hal pengelolaan tentang keselamatan dan keamanan laboratorium. Upaya menjaga keselamatan kerja bertujuan untuk mencegah kemungkinan terjadinya kecelakaan sewaktu bekerja di laboratorium dan penanganannya bila terjadi kecelakaan (Sangi, M., S., dan Adey, T., 2018).

Berdasarkan survei awal di SMA 1 Pangkalan Baru, Kampar, diperoleh informasi bahwa sekolah sudah memiliki laboratorium IPA namun alat dan bahan yang dimiliki kurang tertata dan teradministrasi dengan baik. Hal ini disebabkan karena umumnya para guru IPA kurang menguasai teknik mengelola alat dan bahan, serta keselamatan dan keamanan kerja di laboratorium. Selain itu, di sekolah juga belum tersedia petugas laboratorium yang memiliki kualifikasi pendidikan laboran. Hal tersebut menunjukkan bahwa permasalahan laboratorium sekolah tidak hanya pada keterbatasan fasilitas laboratorium saja, tetapi juga pada manajemen laboratorium.

Keselamatan dan keamanan kerja di laboratorium memerlukan perhatian khusus dan harus diterapkan pada setiap pelaksanaan praktikum di laboratorium. Selain pemakaian bahan dan alat, penyebab utama terjadinya kecelakaan kerja di laboratorium adalah kelalaian atau kecerobohan. Upaya untuk mencegah terjadinya kecelakaan perlu dilakukan dengan cara mengembangkan kesadaran akan pentingnya keselamatan dan kemananan kerja di laboratorium. Keselamatan kerja di laboratorium perlu diinformasikan untuk mengetahui sumber bahaya di laboratorium dan akibat yang ditimbulkan serta cara penanggulangannya. Hal tersebut perlu dijelaskan kepada guru dan siswa agar lebih meningkatkan kewaspadaan selama bekerja di laboratorium. 


\section{METODE}

Metode yang digunakan dalam kegiatan pengabdian masyarakat ini adalah ceramah dan demonstrasi. Metode ceramah digunakan untuk memberikan pengetahuan tentang organisasi dan administrasi laboratorium serta tentang keselamatan dan keamanan di laboratorium IPA terkait tata kelola alat-alat dan bahan laboratorium IPA. Metode demonstrasi digunakan untuk memberikan praktek/simulasi tentang cara penyimpanan dan penyusunan bahan-bahan laboratorium.

Adapun tahapan dalam kegiatan pengabdian masyarakat ini adalah sebagai berikut : (a) Persiapan kegiatan, tim pelaksana kegiatan berkoordinasi dengan pihak sekolah tentang tempat, waktu dan bentuk kegiatan pengabdian yang akan dilakukan (b) Sosialisasi kegiatan, pihak sekolah memberikan informasi kepada siswa tentang kegiatan pengabdian yang akan dilaksanakan (c) Penyuluhan, kegiatan ini dilakukan dengan metode ceramah menggunakan media power point. Materi yang disampaikan yaitu tentang peraturan dasar laboratorium, penataan alat dan bahan laboratorium, keselamatan kerja laboratorium, dan administrasi laboratorium (d) Demonstrasi, kegiatan ini dilakukan dengan memberikan praktek/simulasi tentang cara penyusunan peralatan dan bahan-bahan kimia di laboratorium (e) Evaluasi kegiatan, kegiatan ini bertujuan untuk mengetahui tingkat keberhasilan dari kegiatan pengabdian yang telah dilakukan. Parameter keberhasilan dilihat dari adanya peningkatan pengetahuan peserta. Evaluasi kegiatan dilaksanakan dengan memberikan pre test dan post test terkait materi yang telah diberikan.

\section{HASIL DAN PEMBAHASAN}

Kegiatan pengabdian masyarakat ini bertujuan untuk memberikan edukasi tentang manajemen laboratorium khususnya organisasi dan administrasi laboratorium serta memberikan edukasi tentang keselamatan dan keamanan di laboratorium IPA. Kegiatan ini dilaksanakan pada tanggal 23 Januari 2020 dengan peserta kegiatan merupakan siswa kelas XII yang berjumlah 23 orang.

Secara umum, kegiatan pengabdian masyarakat ini berjalan dengan lancar. Pihak sekolah berpartisipasi secara aktif dalam kegiatan mulai dari perizinan, penyediaan tempat dan waktu, pelaksanaan kegiatan dan juga aplikasi dari hasil kegiatan. Adapun rincian acara dari kegiatan yang dilakukan adalah sebagai berikut : (a) Pembukaan dan pengarahan dari perwakilan pihak sekolah sebagai bentuk acara seremonial (b) Ceramah, kegiatan ini merupakan kegiatan pemberian materi tentang keselamatan dan keamanan di laboratorium kepada siswa menggunakan media power point. Kegiatan ini juga meliputi sesi diskusi (c) Demonstrasi, kegiatan ini merupakan praktek/simulasi tentang cara penggunaan alat-alat gelas di laboratorium dengan baik dan benar. Kegiatan ini dilakukan oleh mahasiswa Universitas Islam Riau. (d) Evaluasi, kegiatan ini dilakukan dengan memberikan pertanyaan kepada siswa tentang materi yang telah diberikan. Kegiatan ini bertujuan untuk mengetahui tingkat pemahaman siswa terhadap keselamatan dan keamanan kerja di laboratorium. (e) Penutupan, kegiatan diakhiri dengan pemberian bantuan berupa safety shooes kepada pihak sekolah dan foto bersama. Dalam rangka keberlanjutan program, maka dilakukan MoA antara pihak sekolah dengan instititusi tim pengabdian sehingga komunikasi dapat tetap berlangsung dengan baik. Dengan demikian, diharapkan kebijakan yang akan dibuat pihak sekolah tentang aturan keselamatan dan keamanan praktikum di laboratorium IPA dapat diterapkan dengan baik oleh guru IPA dan juga siswa. Dokumentasi kegiatan dapat dilihat pada Gambar di bawah ini. 


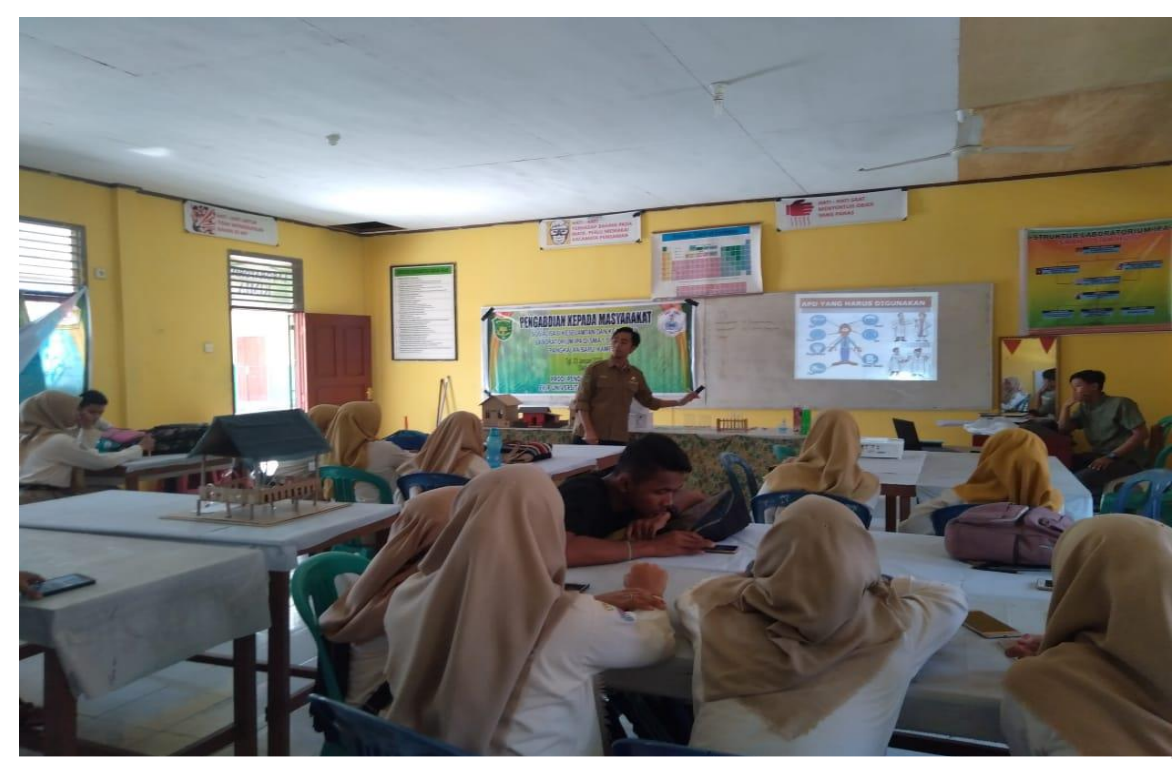

Gambar 1. Penyampaian Materi Kegiatan

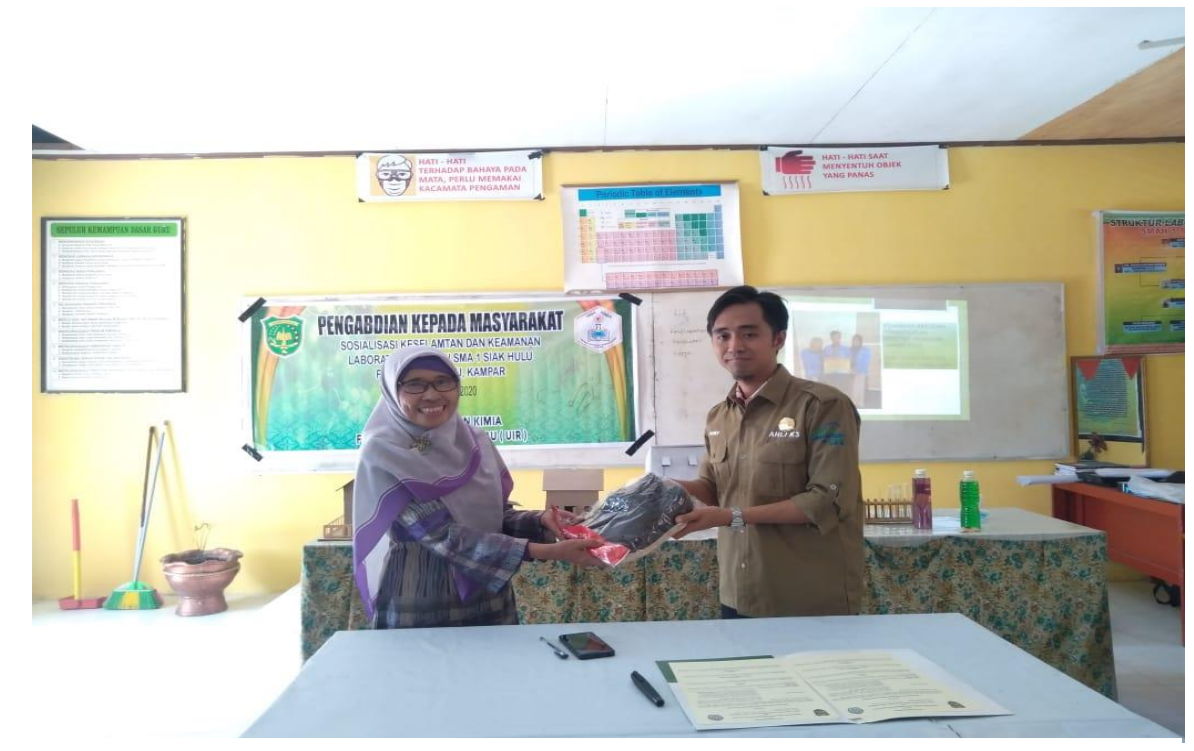

Gambar 2. Pemberian Bantuan Safety Shoes dan Penandatanganan MoA

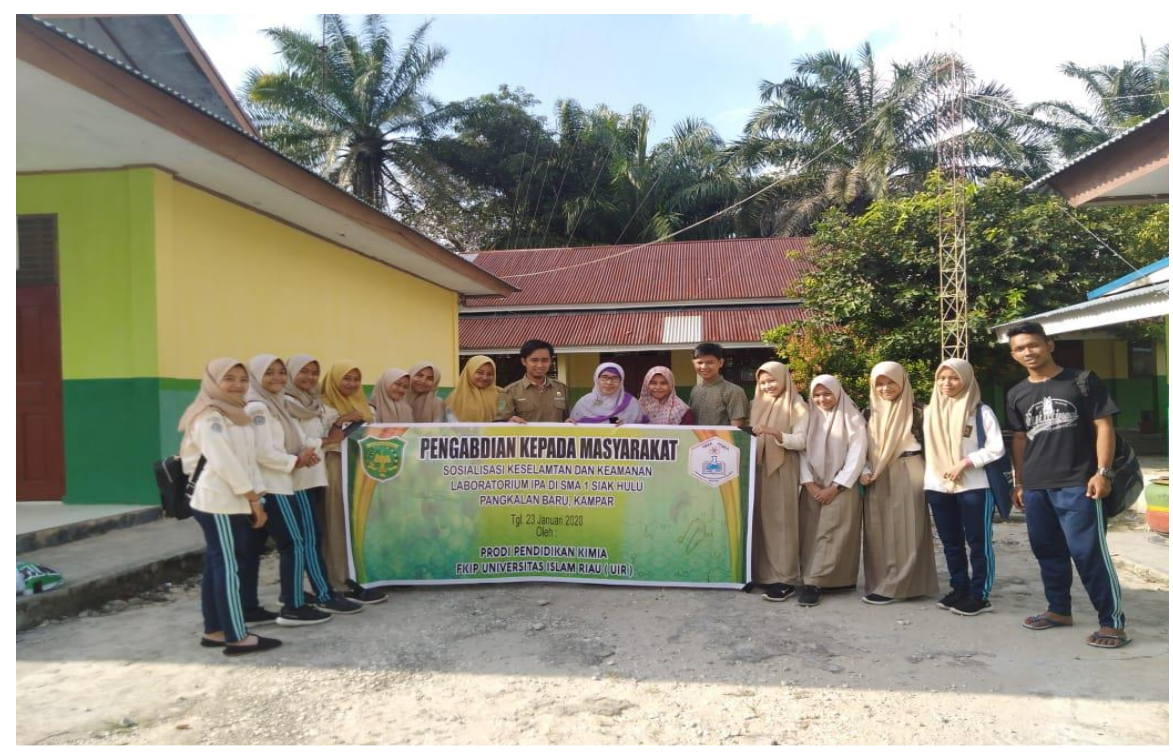

Gambar 3. Foto Bersama Peserta Kegiatan 
Evaluasi hasil kegiatan dilakukan untuk mengetahui tingkat keberhasilan dari kegiatan. Evaluasi dilakukan dengan memberikan pre test dan post test kepada siswa tentang pertanyaan-pertanyaan yang terkait materi yang diberikan. Pengukuran pada pre test dan post test menggunakan kuisioner yang terdiri dari 10 pertanyaan. Jika jawaban benar, mendapatkan nilai 1, dan jika jawaban salah, mendapatkan nilai 0. Oleh karena itu, nilai maksimal yang diperoleh oleh setiap peserta adalah 10 dan nilai minimal adalah nol. Hasil pengukuran tersebut dapat dilihat pada tabel di bawah ini.

Tabel 1. Hasil Pengukuran Pengetahuan Siswa

\begin{tabular}{lcccc}
\hline & N & Skor Total & Mean & $\Delta$ Mean \\
\hline Pre Test & 23 & $92(40 \%)$ & 4 & 3,6 \\
Post Test & 23 & $175(76 \%)$ & 7,6 & \multirow{2}{*}{} \\
\hline
\end{tabular}

Berdasarkan tabel di atas dapat dilihat bahwa terdapat kenaikan nilai rata-rata pengetahuan siswa sebesar sebesar 3,6 dan kenaikan nilai total sebesar 36\%. Nilai total pengukuran pre test sebesar 92 atau $40 \%$ dan nilai total pengukuran post test sebesar $76 \%$. Berdasarkan hasil evalusi tersebut dapat dikatakan bahwa terjadi peningkatan pengetahuan siswa tentang keselamatan dan keamanan laboratorium IPA setelah mengikuti kegiatan pengabdian masyarakat ini.

\section{KESIMPULAN} berikut :

Dari kegiatan pengabdian masyarakat yang telah dilakukan dapat disimpulkan sebagai

1. Secara umum kegiatan berjalan dengan baik dan lancar terlihat dari peserta kegiatan sangat antusias dan berpartisipasi secara aktif dalam kegiatan ini dari awal sampai akhir kegiatan.

2. Kegiatan pengabdian ini juga telah mampu meningkatkan pengetahuan peserta kegiatan tentang keselamatan dan keamanan kerja di laboatorium.

\section{UCAPAN TERIMA KASIH}

Penulis mengucapkan terima kasih kepada Lembaga Penelitian dan Pengabdian Masyarakat (LPPM) Universitas Islam Riau yang telah memberi dukungan financial terhadap pengabdian ini.

\section{DAFTAR PUSTAKA}

Dewan Ilmu Pengetahuan dan Teknologi Kimia. (2010). Keselamatan dan Keamanan Laboratorium Kimia. Washington DC : The National Academic Press.

Erna, M., Johni, A., dan Sri, W., A. (2020). Peningkatan Keterampilan Guru Kimia Melalui Pembuatan Modul Praktikum Berbasis Problem Based Learning. Dinamisia : Jurnal Pengabdian Kepada Masyarakat, 4(1), 120-126.

Isnainy, H., Hamzah, H., dan Rico, J., S. (2014). Implementasi Keselamatan dan Kesehatan Kerja di Laborataorium Kimia Fakultas Matematika dan Ilmu Pengetahuan Alam Universitas Sriwijaya Tahun 2009. Jurnal Ilmu Kesehatan Masyarakat, 5(1) : 19-24.

Mauliza, Ratih, P., S., dan Nurhafidhah. (2017). Keselamatan dan Keamanan Kerja serta Pencegahan Kecelakaan Kerja di Laboartorium. Prosiding Seminar Nasional Politeknik Negeri Lhokseumawe, 1(1) : 374-379.

Panggabean, F., T., M., Kawan S., dan Murniaty, S. (2017). Pengembangan dan Aplikasi Pengelolaan Laboratorium Kimia Berbentuk Virtual Lab. Prosiding Seminar Nasional Pengabdian Masyarakat LPM UNIMED 2017, 12-15. 
Raharjo. (2017). Pengelolaan Alat Bahan dan Laboratorium Kimia. Jurnal Kimia Sains dan Aplikasi, 20 (2) : 99-104.

Rahmantiyoko, A., dkk, (2019). Keselamatan dan Keamanan Kerja Laboratorium. IPTEKJournal of Proceedings Series, 4 : 36-38.

Sangi, M., S., dan Adey, T. (2018). Keselamatan dan Keamanan Laboratorium IPA. Jurnal MIPA UNSRAT, 7(1) : 20-24.

Sinaga, M., Z., E., Yuan, A., S., dan Aghni, S. (2018). Optimalisasi Laboratorium IPA Untuk Meningkatkan Minat Belajar Siswa di SMP Swasta Islam Terpadu Iqra' Medan. Abdimas Talenta, 3(2) : 326-330.

Subiantoro, A., W. (2011). Keselamatan dan Kesehatan Kerja di Laboratorium Sains, disampaikan dalam Pelatihan Pengelolaan Laboratorium Sains sekolah bagi Guru-guru Sains SMP/MTs Kabupaen Temanggung, di FMIPA UNY. 